\section{EU supports delay in reducing doctors' hours}

Linda Beecham, $B M J$

The European Union's Council of Ministers has agreed to delay until 2012 the full implementation of the European 48 hour working time directive to the hours worked by junior hospital doctors.

The European Commission had proposed that junior doctors' hours should be reduced to a maximum of 54 hours a week for seven years followed by implementation of the directive. The new agreement, which was leaked last month (15 May, p 1307), means that the hours will remain the same for four years (with no maximum limit) and then reduce to a maximum of 60 for three years, 56 for three years, and 52 for three years, before reducing finally to a maximum of 48 .

The United Kingdom and Republic of Ireland argued that the longer phasing in time was necessary to enable enough doctors to be trained as consultants to cope with the shorter working weeks.

The UK health secretary, Frank Dobson, said that the agreement was "good news for junior doctors and good news for the NHS." He said that no junior doctor would have to work longer than at present. "The directive's objective must be brought in gradually to maintain the high standard of junior education and to safeguard patient care," he added.

The decision has to be voted on by the newly elected European parliament later this year, and the BMA will be lobbying members of parliament.

Mr Andrew Hobart, chairman of the BMA's Junior Doctors Committee, said: "We are extremely disappointed that there is to be no legal limit to reduce junior doctors' hours for the next four years. In 1991 the new deal for junior doctors set a limit of 56 working hours, with an implementation date of December 1996, and yet two years later there are still thousands of junior doctors working beyond this limit.

"We will have to wait for seven years to get a legal obligation to reduce junior doctors' hours to the new deal restriction. The only limit that junior doctors will now be working to is the 168 hours that there are in a week."

The European Union's social affairs commissioner, Padraig Flynn, said that he was "very, very dismayed" at the decision. He said that it was unacceptable for patients to be treated by doctors who were exhausted and that such a long transitional period was "not politically feasible or morally acceptable. It does not take 13 years to improve work organisation in European hospitals."

\section{Scotland}

\section{appoints health minister}

Bryan Christie, Edinburgh

Scotland's newly appointed health minister, Susan Deacon, a former business consultant, has experienced a meteoric political rise over the past year. Initially she was rejected by the Labour party as a candidate for the Scottish parliament but she won an appeal. She was then selected and won a parliamentary seat and now has been appointed as health minister.

Her own background is in local government and education, and she has no previous experience of working in the health service. She replaces the former neurosurgeon, Sam Galbraith, who has moved to education.

Ms Deacon is keen to foster a new spirit of open and accessible government. She said that there were substantial areas of agreement on health across all the political parties and added: " I think the formulation of health policy is an area in which we have an opportunity to develop the new politics."

Labour has entered into a coalition with the Liberal Democrats to run the new parliament, and the health policy that has been adopted combines elements of both parties' manifestos. It includes the establish- ment of a health promotion fund to finance initiatives aimed at improving public health and the creation of an independent Scottish Inspectorate of Health and Social Care. Doctors' leaders have welcomed Ms Deacon's appointment.

Arthur Morris, the chairman of the Scottish Council of the British Medical Association said: "The challenge of the new Scottish Parliament is for the government, the medical profession, the parliament, and the people to forge a partnership that will take the politics out of health and build a national consensus on creating the best health service for patients."

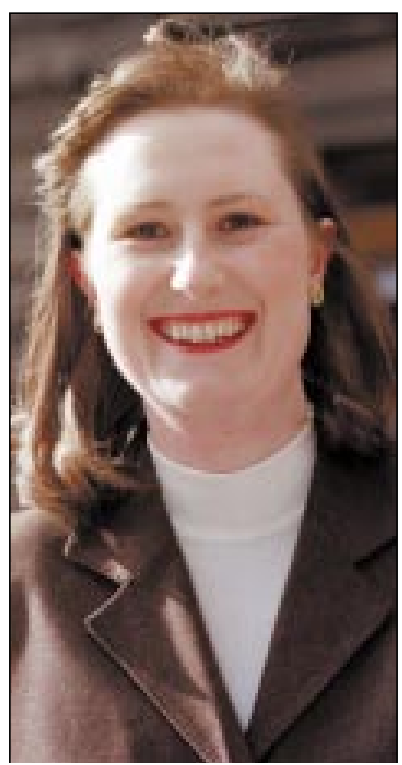

Susan Deacon: new health minister for Scotland

\title{
Scare tactics cut smoking rates in Australia to all time low
}

Simon Chapman, Sydney

Australia's smoking rate, which was stalled throughout the 1990 s with around $25 \%$ of adults found in several surveys to be smoking, has recommenced its downward slide. The national prevalence of adult smoking has now fallen to $22 \%$, the lowest figure ever recorded.

Australia, like the United Kingdom, Canada, and the United States had experienced a decade long lull in its decline in the prevalence of smoking.

On World No Tobacco Day this week, health minister Michael Wooldridge announced the results of the evaluation of the controversial "Every cigarette is doing you damage" national media campaign which ran from June to November 1997 , and which cost $\$ \mathrm{~A} 7 \mathrm{~m}$ $(£ 2.9 \mathrm{~m} ; \$ 4.6 \mathrm{~m})$.

The campaign has run sporadically since 1997 . The television advertisements took viewers inside the bodies of smokers in their 30s to see the damage caused by smoking.

The advertisement found to be most motivating to smokers showed a surgeon's gloved hand squeezing a yellow atheroma out of an aorta at necropsy. Described by smokers as something you "see once and never forget," the advertisements have renewed debate about the conventional wisdom that scare tactics "don't work" in health promotion.

Scare campaigns have also been used to spearhead the public awareness component of Australia's road safety campaign, which has similarly seen the toll of road deaths reach its lowest point.

All of the antismoking television advertisements gave viewers a telephone number on quitting smoking; the evaluation of the campaign reports that 1 in 4 callers continued to abstain from smoking one year later.

Although the campaign was targeted at adult smokers, evidence emerged that it had also had a powerful effect on teenagers. The campaign is now being run in Massachusetts, United States; Singapore; New Zealand; and British Columbia.

In September last year, deregulation of nicotine replacement treatment saw two pharmaceutical companies, Pharmacia Upjohn and SmithKline Beecham, together spend more than the government on advertising directly to consumers. Sales of nicotine replacement therapy aids rose spectacularly as a result.

Further information can be found at www.quitnow.info.au. 